in vivo $34: 3137-3152(2020)$

doi:10.21873/invivo.12148

Review

\title{
Specialized Histological and Histomorphometrical Analytical Methods for Biocompatibility Testing of Biomaterials for Maxillofacial Surgery in (Pre-) Clinical Studies
}

\author{
CAROLIN LINDNER $^{1 *}$, ANNICA PRÖHL $^{1 *}$, MANUEL ABELS $^{1}$, TOM LÖFFLER $^{1}$, \\ MILIJANA BATINIC ${ }^{1}$, OLE JUNG $^{2 *}$ and MIKE BARBECK ${ }^{1 *}$ \\ ${ }^{1}$ BerlinAnalytix GmbH, Berlin, Germany; \\ ${ }^{2}$ Clinic for Dermatology and Venereology, Rostock University Medical Center, Rostock, Germany
}

\begin{abstract}
Both preclinical in vivo experiments and clinical trials are indispensable for analysis of tissue reactions in evaluating the compatibility of biomaterials or medical devices, i.e. the cell types interacting with the material, integration or degradation behavior, implant bed vascularization and immunological response. In particular, both the histological workup (including the processes such as embedding, cutting, histochemical and immunohistochemical staining methods), as well as qualitative and quantitative analysis are crucial steps enabling the final evaluation of biocompatibility. We present a short overview of the most important steps of the different workup and analytical methods used in preclinical and clinical biopsies for both novice and experienced researchers in the field of biomaterial science.
\end{abstract}

A broad variety of biomaterials is on the market and in daily clinical use. Moreover, many different materials are under development or in the process of authorization. Already available materials need clinical follow-up analyses of their efficacy in post market surveillance. In contrast, analyses of both the biocompatibility and the mode of action of precursor materials have to be conducted during the development process and especially prior to their market introduction.

This article is freely accessible online.

*These Authors contributed equally to this study.

Correspondence to: Dr. rer. nat. Mike Barbeck, BerlinAnalytix $\mathrm{GmbH}$, Ullsteinstrasse 108, 12109 Berlin, Germany. E-mail: mike.barbeck@berlinanalytix.com

Key Words: Histology, biopsies, histological workup, histochemical staining, immunohistochemistry, histomorphometry, review.
In this context, the histological analysis of tissue explants and biopsies is still of enormous importance, even in the case of implantable biomaterials such as bone substitutes or collagen-based materials, due to the limited possibilities to analyze their interactions with the organism and their regenerative capacities in the case of other analytical methods such as micro-computed tomography (1). Moreover, an analysis of their mechanisms of (cellular) degradation is also of special importance as it is most often directly associated with their biological or regenerative functionality.

Different tissue reactions and degradation patterns have already been shown for both bone substitutes or collagenbased materials, indicating their different clinical use for various indications (2-5). This varying resorption behavior may result from different physicochemical material characteristics due to the broad spectrum of purification processes in the case of natural materials or synthesis processes in the case of synthetic materials $(3,6,7)$. In this context, it is already well known that every biomaterial induces an inflammatory response and inflammatory tissue response cascade, the so-called 'foreign body' reaction to biomaterials (7-10). This process is extremely specific for each biomaterial because it depends on its respective physicochemical characteristics which interact in different ways with the components of the immune system (7). In this inflammatory cascade, macrophages are key cellular components because they regulate different processes in the implantation bed (7-10). Moreover, their fused end stage, the multinucleated giant cell (MNGC), is sometimes found within the implantation beds of biomaterials (7-10). Both macrophages and MNGCs express pro- and anti-inflammatory molecules, such as vascular endothelial growth factor (VEGF) and heme oxygenase, which have major influence on vascularization of the implant bed of a bone substitute material $(8,11)$. Vascularization is a key factor for bone-tissue 
regeneration and osteoconduction; thus, the inflammatory response to a material is connected with the bone-healing process and other various pathways $(8,9)$. For example, the inflammatory reaction is also related to the process of biomaterial degradation as both macrophages and MNGCs are mainly involved in material phagocytosis $(3,8,9)$.

Further development in the field of biomaterials is necessary to create materials that are more adaptive to the respective (micro-) milieu. Preclinical and clinical studies most often require evaluation of the three different processes: Regenerative effects of biomaterials, analysis of the materialspecific inflammatory tissue response, and analysis of material degradation. Starting with the histological workup (including processes such as embedding, cutting, histochemical and immunohistochemical staining methods), as well as qualitative and quantitative analytical methods, the different methodologies are used in crucial steps which enable the final evaluation of the biocompatibility of a biomaterial. Here we give a short overview of the most important steps of the different workup and analytical methods of preclinical and clinical biopsies. Bone substitute materials are used as example materials.

\section{(Pre-) treatment of Biopsies}

The first vital step is the fixation of tissue samples, which prevents autolysis or putrefaction (12-14). It is important to determine which components within a biopsy will be analyzed because this affects the choice of the fixation reagent. The fixation process must terminate biochemical reactions within the tissue sample while preserving the cells or tissues in as close as possible to their natural state (1214). Different fixation techniques exist for further detection of respective tissue components $(12,13)$ (Table I).

The most common fixative used in histology is formaldehyde, which is normally used as neutral buffered formalin, i.e. 3.7-4.0\% formaldehyde in phosphate-buffered saline $(12,13)$. Formaldehyde fixes tissue via cross-linking of proteins, which may lead to issues with further detection of epitopes via immunohistochemistry (13). This process can mostly be reversed using a simple water treatment. Special retrieval methods, such as ultrasonic, enzymatic, or heat treatments, among others, can also be applied to restore the natural state of epitopes $(12,13)$. In general, using formaldehyde allows for good fixation of the tissue sample and for the use of many stains in the field of bone regeneration. For tissue specimens that are to undergo immunohistochemical staining, different special fixative solutions are available, which might be more favorable as no treatment due to cross-linking processes is necessary for immunohistochemistry $(12,13,15)$.

After this initial fixation step, the embedding technique is important for the sectioning of tissue samples. The hardness

Table I. Different fixatives and related target structures.

\section{Fixation method}

Neutral buffered formalin, paraformaldehyde

Frozen sections

Frozen sections, glutaraldehyde

Alcoholic fixatives, HOPE fixation

Frozen sections

Bouin solution, neutral buffered formalin

HOPE: HEPES-glutamic acid buffer-mediated organic solvent protection effect.

of the tissue dictates the embedding technique because the embedding medium should optimally have the same or similar hardness as the specimen to enable sectioning. In general, for soft-tissue samples including biomaterials such as collagen membranes, paraffin embedding is the best choice. Once fixed, tissue needs to be processed using gentle agitation, usually on a tissue processor (Figure 1A), for around $17 \mathrm{~h}$ as detailed in Table II.

Other different tissue-processing protocols are described (16, 17), and their use and duration is dependent on the size of the biopsy that needs to be completely saturated by the agents or by the tissue type. Furthermore, the choice of the tissueprocessing protocol is dependent on the subsequent staining procedure. This means that special staining methods such as some immunohistochemical staining methods or special staining techniques such as colloidal gold cytochemistry also require specialized processing techniques (18).

Afterwards, embedding of a biopsy can be undertaken. Tissues have to be embedded in a harder medium both as a support and to allow the cutting of thin tissue slices. The choice of the embedding medium depends on the type of tissue and at least also on the type of microtomy. Paraffin is the most commonly used embedding medium in histopathology. However, for cutting of hard tissue samples, including hard materials such as bone substitutes or metalbased materials, embedding in plastic is a further option. Both methods are described below.

Paraffin wax. The waxes used for histological preparation are mixtures of purified paraffin wax and various additives such as resins. Different wax formulations allow for different types of embedding, depending on the properties of the respective biopsy sample (19). The optimal wax formulation should possess physical properties comparable to those of embedded tissue or biomaterial (19).

Paraffin wax is usually a mixture of straight-chain or $n$ alkanes with a carbon chain length of between 20 and 40 . The wax is a solid at room temperature but has melting points at different temperatures, the most common for histological use being about $56-58^{\circ} \mathrm{C}$. The traditional advice with paraffin wax is to use it at about $2^{\circ} \mathrm{C}$ above its melting point. 

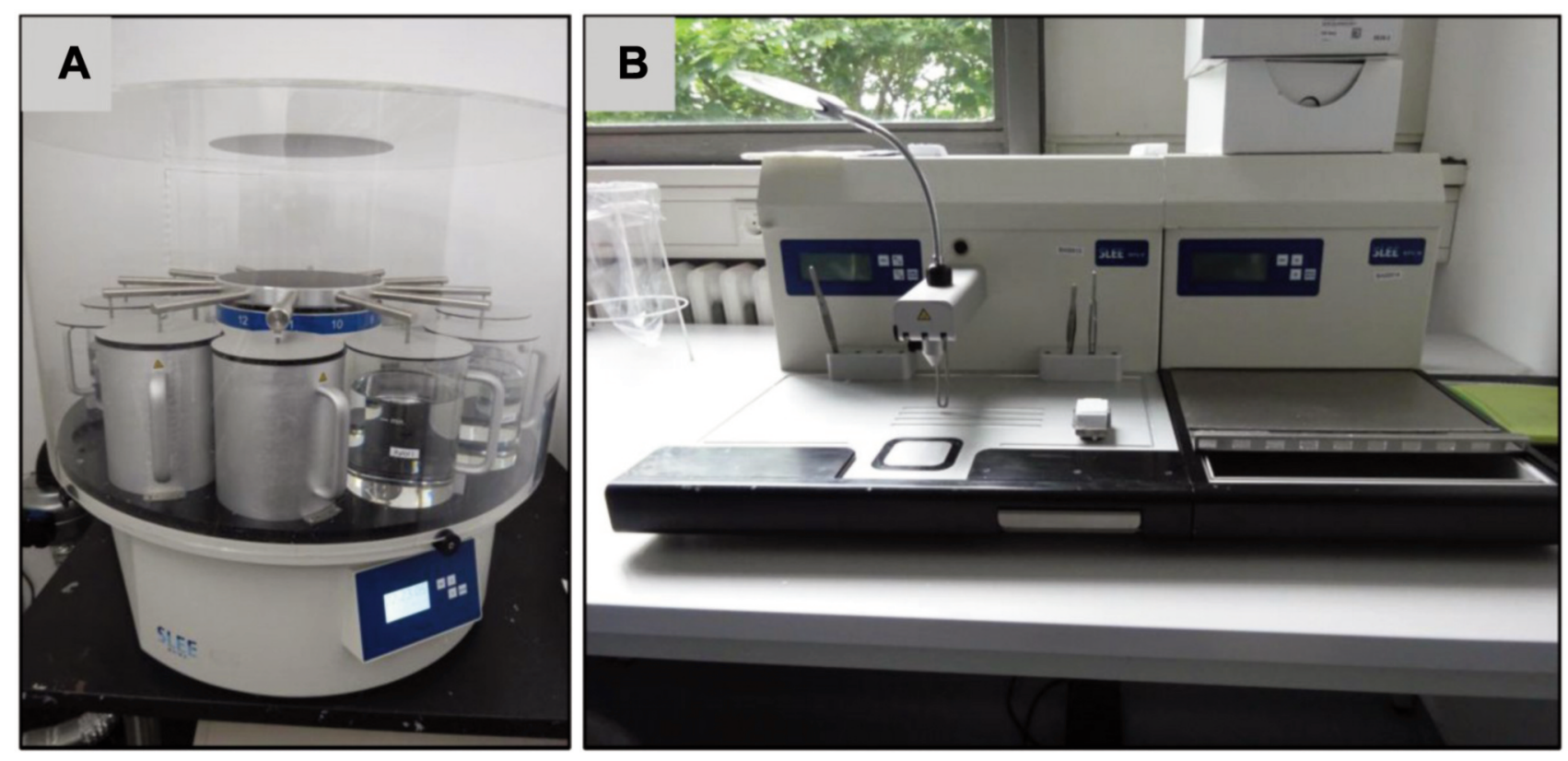

Figure 1. Exemplary images of a tissue processor (A) and a paraffin embedding station (B).

The paraffin-embedding process should be conducted as follows and optimally an embedding station (Figure 1B) is used.

i. Open the cassette to view the tissue sample and choose a mold that best corresponds to the size of the tissue. A margin of at least $2 \mathrm{~mm}$ of paraffin surrounding all sides of the tissue gives the best cutting support. Discard the cassette lid.

ii. Put a small amount of molten paraffin in the mold, dispensing from the paraffin reservoir.

iii. Using warm forceps, transfer the tissue into the mold, placing the cut side down, as it was placed in the cassette.

iv. Transfer the mold to a cold plate, and gently press the tissue flat. Paraffin will solidify in a thin layer which holds the tissue in position.

v. When the tissue is in the desired orientation add the labeled tissue cassette on top of the mold as a backing. Press firmly.

vi. Hot paraffin is added to the mold from the paraffin dispenser. Be sure there is enough paraffin to cover the face of the plastic cassette.

vii. If necessary, fill the cassette with paraffin while cooling, keeping the mold full until solid.

viii. When the wax is completely cooled and hardened (30 min) the paraffin block can easily be popped out of the mold; the wax blocks should not stick.

One of the enormous advantages of paraffin embedding is its maximum of flexibility as it allows to simply melt the tissue block again and start over if the wax cracks or the biopsy is not aligned well.
Table II. Standard tissue processing protocol.

\begin{tabular}{lc}
\hline Chemical substance & Duration \\
\hline $70 \%$ Ethanol & $1 \mathrm{~h}$ \\
$70 \%$ Ethanol & $1 \mathrm{~h}$ \\
$80 \%$ Ethanol & $1 \mathrm{~h}$ \\
$95 \%$ Ethanol & $1 \mathrm{~h}$ \\
$100 \%$ Ethanol & $1.5 \mathrm{~h}$ \\
$100 \%$ Ethanol & $1.5 \mathrm{~h}$ \\
$100 \%$ Ethanol & $1.5 \mathrm{~h}$ \\
Xylene or xylene substitute & $1.5 \mathrm{~h}$ \\
Xylene or xylene substitute & $1.5 \mathrm{~h}$ \\
Xylene or xylene substitute & $1.5 \mathrm{~h}$ \\
Paraffin wax $\left(58-60^{\circ} \mathrm{C}\right)$ & $2 \mathrm{~h}$ \\
Paraffin wax $\left(58-60^{\circ} \mathrm{C}\right)$ & $2 \mathrm{~h}$ \\
Total & $17 \mathrm{~h}$ \\
\hline
\end{tabular}

Moreover, paraffin embedding is also an option for biopsies of hard tissue because an initial decalcification process can also allow for sectioning of hard tissue samples or samples including bone substitute materials $(14,20)$. However, most often the bone substitute material is eluted during the decalcification process. In most cases, the tissue interface at the surfaces of former bone substitute material can be histologically examined. Three main types of decalcifying agents are used: (a) Strong mineral acids, (b) weaker organic acids, or (c) chelating agents (18). Strong acids, such as hydrochloric or nitric acid, provide the most 
Table III. Exemplary dehydration and (pre-) infiltration process for hard tissue samples.

\begin{tabular}{lccc}
\hline Phase & Solution & Concentration & $\begin{array}{c}\text { Time/ } \\
\text { temperature }\end{array}$ \\
\hline Dehydration 1 & Ethanol & $70 \%$ & $>1 \mathrm{~h} / \mathrm{RT}$ \\
Dehydration 2 & Ethanol & $80 \%$ & $>1 \mathrm{~h} / \mathrm{RT}$ \\
Dehydration 3 & Ethanol & $96 \%$ & $>1 \mathrm{~h} / \mathrm{RT}$ \\
Dehydration 4 & Ethanol & $96 \%$ & $>1 \mathrm{~h} / \mathrm{RT}$ \\
Dehydration 5 & Ethanol & $100 \%$ & $>1 \mathrm{~h} / \mathrm{RT}$ \\
Dehydration 6 & Ethanol & $100 \%$ & $>1 \mathrm{~h} / \mathrm{RT}$ \\
Dehydration 7 & Ethanol & $100 \%$ & $>1 \mathrm{~h} / \mathrm{RT}$ \\
Intermedium 1 & Xylol & - & $>1 \mathrm{~h} / \mathrm{RT}$ \\
Intermedium 2 & Xylol & - & $>1 \mathrm{~h} / \mathrm{RT}$ \\
Pre-infiltration 1 & Xylol/Technovit & - & $>1 \mathrm{~h} / \mathrm{RT}$ \\
Pre-infiltration 2 & Technovit ${ }^{\circledR}$ 9100 Basic & - & $>1 \mathrm{~h} / \mathrm{RT}$ \\
(Last phase in & (stab.)+Hardener 1 & & \\
machine) & Technovit ${ }^{\circledR} 9100$ & & \\
Pre-infiltration 3 & (destab.)+Hardener 1 & - & $>1 \mathrm{~h} / 4^{\circ} \mathrm{C}$ \\
(Refrigerator) & Technovit ${ }^{\circledR} 9100$ & & $>1 \mathrm{~h} / 4^{\circ} \mathrm{C}$ \\
Infiltration & & After 5 days, \\
(Refrigerator) & (destab.)+Hardener 1 & - & change \\
& + PMMA powder & & solution \\
& & &
\end{tabular}

RT: Room temperature; stab.: stabilized; destab.: destabilized; PMMA: polymethylmethacrylate.

rapid methods; however, these decalcifiers must be used carefully to prevent tissue damage that may interfere with immunohistochemical detection (20). Decalcifiers based on weak acids, such as formic acid or trichloroacetic acid, can be directly combined with formalin (20). Their application leads to slower decalcification compared with agents based on strong acids but reduces tissue damage (20). Decalcifiers based on chelating agents, such as ethylenediaminetetraacetic acid (EDTA), are preferable because they decalcify via capturing calcium ions from both bone tissue and bone substitutes (15). EDTA allows for mild decalcification of biopsies without damaging the tissue (20). However, using this medium requires a considerable amount of time, i.e. weeks to months, for sufficient decalcification.

Plastic embedding. In contrast, for hard tissue samples, including hard materials such as bone substitutes or metalbased materials, embedding in plastic is preferable; this can maintain harder biomaterials such as bone substitutes within the subsequent histological slides. Epoxy and acrylic resins are usable as embedding media. However, before the hard tissue samples are prepared for plastic embedding it must be decided which kind of plastic is suitable for the planned analysis and especially for the proposed staining techniques. This is because not every plastic embedding medium allows for immunohistochemical staining or the possibilities for immunohistochemical detection are restricted. In this context, methylmethacrylate (MMA) embedding of undecalcified bone biopsies is a technique widely used for bone histomorphometry. However, conventional MMA embedding causes almost complete loss of enzymatic activity and protein antigenicity in tissue samples. Thus, this method is well suited for later histochemical staining, but different antibodies may not work properly after MMA embedding.

Different workarounds or enhancements have been described for MMA embedding which also enable both histochemical staining and immunohistochemical detection $(21,22)$. In general, acrylic resins or glycol methacrylatebased polymers should be used for samples planned to undergo immunohistochemistry (23). In this context, the family of Technovit ${ }^{\circledR}$ embedding kits is most often used in this research field. The Technovit ${ }^{\circledR} 9100$ system is especially appropriate for embedding of not only mineralized tissues, but also soft tissues, and is suitable for both histochemical staining methods and for enzymatic as well as immunohistological examinations. This embedding system is based on MMA, which hardens at low temperature.

Thus, the treatment of biopsies for Technovit ${ }^{\circledR} 9100$ (Heraeus KulzerGmbH, Germany) is exemplarily described below as good results have been achieved and published by our group and others $(2,3,24-27)$. However, other different protocols have also been described in the literature as leading to satisfying results.

Technovit ${ }^{\circledR} 9100$ embedding protocol: Polymerization of the hydrophobic Technovit ${ }^{\circledR} 9100$ occurs by excluding oxygen. Additional components such as polymethylmethacrylate (PMMA) powder and regulator allow for a controlled polymerization in the range of -2 to $-20^{\circ} \mathrm{C}$ (depending on the volume) that guarantees complete dissipation of the heat of polymerization. The Technovit ${ }^{\circledR}$ 9100 embedding system is composed of the following components:

(a) Technovit ${ }^{\circledR} 9100$ Basic Solution - Component 1;

(b) Technovit ${ }^{\circledR} 9100$ PMMA Powder - Component 2;

(c) Technovit ${ }^{\circledR} 9100$ Hardener 1 - Component 3;

(d) Technovit ${ }^{\circledR} 9100$ Hardener 2 - Component 4;

(e) Technovit ${ }^{\circledR} 9100$ Regulator - Component 5;

(f) PMMA granules, EXART ${ }^{\circledR}$.

Prior to embedding, fixation of the biopsy for up to $24 \mathrm{~h}$ is required. Different fixation solutions can be used as follows for detecting antigens/enzymes:

i. $4 \%$ Neutral buffered formalin solution $(0.1 \mathrm{M}$ phosphate or $0.02 \mathrm{M}$ phosphate buffer for iliac crest biopsies)

ii. $10 \%$ Buffered formalin solution (0.1 M phosphate buffer) iii. $1.4 \%$ Paraformaldehyde solution, cold $\left(4-8^{\circ} \mathrm{C}\right)$ for 24-28 h

After the fixation process, dehydration and (pre-) infiltration has to be conducted according to Table III (22): 

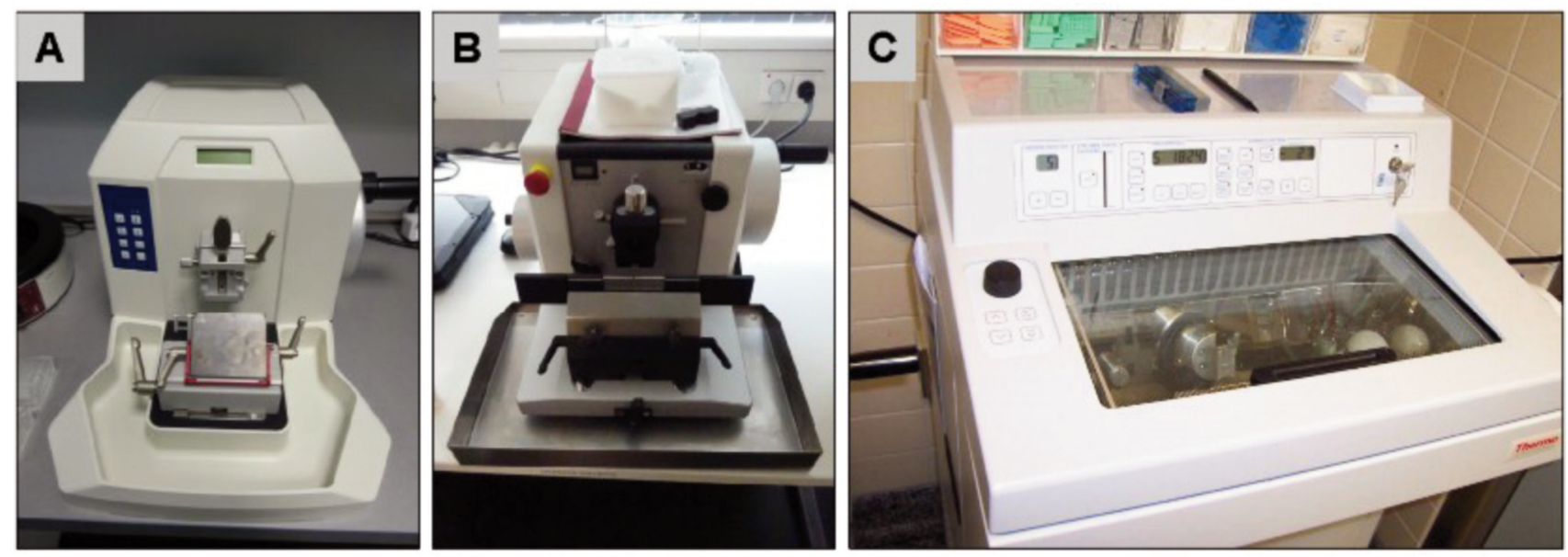

Figure 2. Exemplary images of a rotation microtome for paraffin sectioning (A), a rotation microtome for plastic sectioning $(B)$ and a cryostat $(C)$.

Once the specimens have warmed to room temperature after hardening, the blocks are ready for sectioning with a rotation microtome.

\section{Sectioning of Biopsies}

For both paraffin- and plastic-embedded specimens, further processing includes sectioning on a microtome using different specimen holders and different profiles of microtome blades. Most often, sliding or rotation microtomes are used for sectioning of both paraffin- and plastic-embedded biopsies.

Sliding microtomes are composed of a fixed sample holder and a blade that is fixed on a slide. The cutting blade is pressed through the sample. Sliding microtomes allow cuts with a thickness of 1 to $60 \mu \mathrm{m}$. The main disadvantages of this kind of microtome are that it is not possible to make serial cuts and it is almost impossible to obtain sections with a thickness of less than $8 \mu \mathrm{m}$.

In contrast, rotation microtomes have a fixed blade and a mobile sample holder that is activated by a handwheel. Normally the sample holder of these microtomes moves in the downward direction. The prepared samples accumulate on the blade. The advantage of these microtomes is that the high mass of the flywheel matches the different hardness in the same pass, resulting in a uniform cut. The use of a rotation microtome allows samples between 1 and $60 \mu \mathrm{m}$ to be prepared. The main disadvantage is their high price due to the complexity of the advance mechanism, which also makes repairs more difficult and expensive.

While most rotation microtomes are made for blocks embedded in paraffin (Figure 2A), microtomes for sectioning of plastic-embedded biopsies need to have special features (Figure 2B). Thus, a heavy-duty microtome for hard sections should be used in combination with a special knife holder and knife (Figure 2B).

Other techniques include tissue freezing for cryostat sectioning (28) (Figure 2C). This method includes an initial rapid freezing step (generally using liquid nitrogen) as the fixation method (28). This is the fastest and easiest of all fixation methods and is well-suited for immunohisto-chemistry and other analyses not requiring antigen retrieval $(22,28)$. However, it results in the poorest morphology, depending on the tissue being used, and is prone to developing freezing artifacts caused by delays in the freezing process (29). An additional example of a fixative is $4 \%$ paraformaldehyde, combined with using sucrose as a cryoprotectant (30). This results in excellent tissue morphology, is suitable for immunohistochemistry, and can be combined with a slower freeze in crushed-powder dry-ice alone, slush of dry ice and $100 \%$ alcohol, or in a beaker of isopentane surrounded by dry ice. This method does not tend to incur freezing artifacts or cause cracked blocks (30). However, this technique is very time consuming and requires antigen retrieval due to crosslinking before applying immunohistochemical procedures (31).

Altogether, the respective choice of workup methods is dependent on the technical equipment of the institution or department, and the preferences of the researchers; it also depends on special analytical methods that may require further fixation or embedding techniques.

\section{(Immuno-)Histochemical Staining Methods}

There is a variety of histochemical stains and antibodies for immunohistochemical detection of different extracellular matrix components and cell types. The field of biomaterial and bone substitute research uses a special range of histochemical stains whose application allows different 
important features within the biopsies to be highlighted and enhances tissue contrast.

In the context of biomaterial research, it is most often important to choose a staining that allows for microscopical separation of implanted materials from the surrounding (newly generated) bone or connective tissue. Thus, the staining is highly important for information acquisition.

Hematoxylin and eosin (H\&E) staining is one of the principal stains in histology and is widely used in medical diagnosis (32). Although H\&E is a useful all-purpose stain that is quick and easy to apply, its disadvantages include low differentiation between different tissue components, cell types and implanted biomaterials (33). For more detailed separation, specialized stains are used in this research field. Some of these methods are listed in Table IV (34). Furthermore, some exemplary images of the described staining results are displayed in Figure 3.

However, a variety of other staining methods are available, and are described in the literature, but the choice of staining strongly depends on the biomaterial and the tissue analyzed. It would go beyond the scope of this article to mention all the available staining methods.

One of the best histochemical staining procedures which allows for a high level of differentiation between different tissue components is Movat's pentachrome stain $(35,36)$. The protocol for this staining method that is suitable for most histological analyses is presented in the following:

\section{Materials}

- Alcian blue $1 \%$

- Alkaline alcohol with ammonia

- Weigert's iron hematoxylin components A and B

- Iron (III) chloride solution (for $5 \mu \mathrm{m}$ sections)

- Sodium thiosulfate 5\% (for $5 \mu \mathrm{m}$ sections)

- Brilliant Crocein acid fuchsin

- Phosphotungstic acid 5\%

- Acetic acid 1\% (10 ml 100\% acetic acid + $990 \mathrm{ml}$ distilled water)

- Safron du Gatinais

Notes:

- Work under the hood

- Wear protective clothing (laboratory coat, gloves and safety glasses)

- The staining must be carried out in cuvettes

- Acetic acid 1\% (stock 1 1: $10 \mathrm{ml}$ 100\% acetic acid + 990 $\mathrm{ml}$ distilled water)

\section{Preparations:}

- Alcian blue: check the $\mathrm{pH}$ value for 2 and correct if necessary using $\mathrm{NaOH} / \mathrm{HCl}(0.1-1 \mathrm{~mol} / \mathrm{l})$

- Weigert's iron hematoxylin: Consists of component A and B (Weigert's solution A - alcoholic hematoxylin solution;
Table IV. Different histochemical stains and their advantages.

\begin{tabular}{ll}
\hline Staining method & \multicolumn{1}{c}{ Advantages } \\
\hline Masson-Goldner & - Differentiation between mature bone, new \\
original & formed bone, fibrous tissue, cartilage tissue, \\
& and bone substitutes \\
& - Detection of blood vessels based on the color \\
& of erythrocytes \\
& - Green connective tissue counterstaining \\
& - Differentiation between mature bone, newly- \\
& formed bone, fibrous tissue, cartilage tissue, \\
and bone substitutes \\
Godified Masson- \\
Goldner trichrome & - Blue connective tissue counterstaining \\
& - Highest degree of differentiation due to use \\
of five dyes for analysis of bone healing and \\
pontachrome
\end{tabular}

Weigert's solution B - hydrochloric acid iron(III)nitrate solution).

Preparation of the working solution from component $\mathrm{A}$ and B: Mix solutions $\mathrm{A}$ and $\mathrm{B}$ in equal parts, e.g. $125 \mathrm{ml}$ solution A $+125 \mathrm{ml}$ solution B for a $250 \mathrm{ml}$ staining cuvette.

- Store Safron du Gatinais for $24 \mathrm{~h}$ at $60^{\circ} \mathrm{C}$ in a warming cabinet for color extraction, leave the sediment in the bottle.

- Fix paraffin sections at $60^{\circ} \mathrm{C}$ in a heating cabinet for at least 30-45 $\mathrm{min}$

- Press and dry acrylate sections at $60^{\circ} \mathrm{C}$ in a cabinet.

\section{Staining procedure:}

i. $3 \times$ Xylene or $3 \times$ MEA (plasterer) 5 min each

ii. $2 \times$ Absolute ethanol 2 min rehydration each

iii. $2 \times$ Ethanol $96 \% 2$ min rehydration

iv. $2 \times$ ethanol $80 \% 2$ min rehydration

v. Distilled water 2 min rehydration

vi. Color with Alcian blue 1\% 15 min (note preparation!)

vii. Rinse in tap water 5 min

viii. Alkaline alcohol $1 \mathrm{~h}$

ix. Rinse in tap water $10 \mathrm{~min}$ 

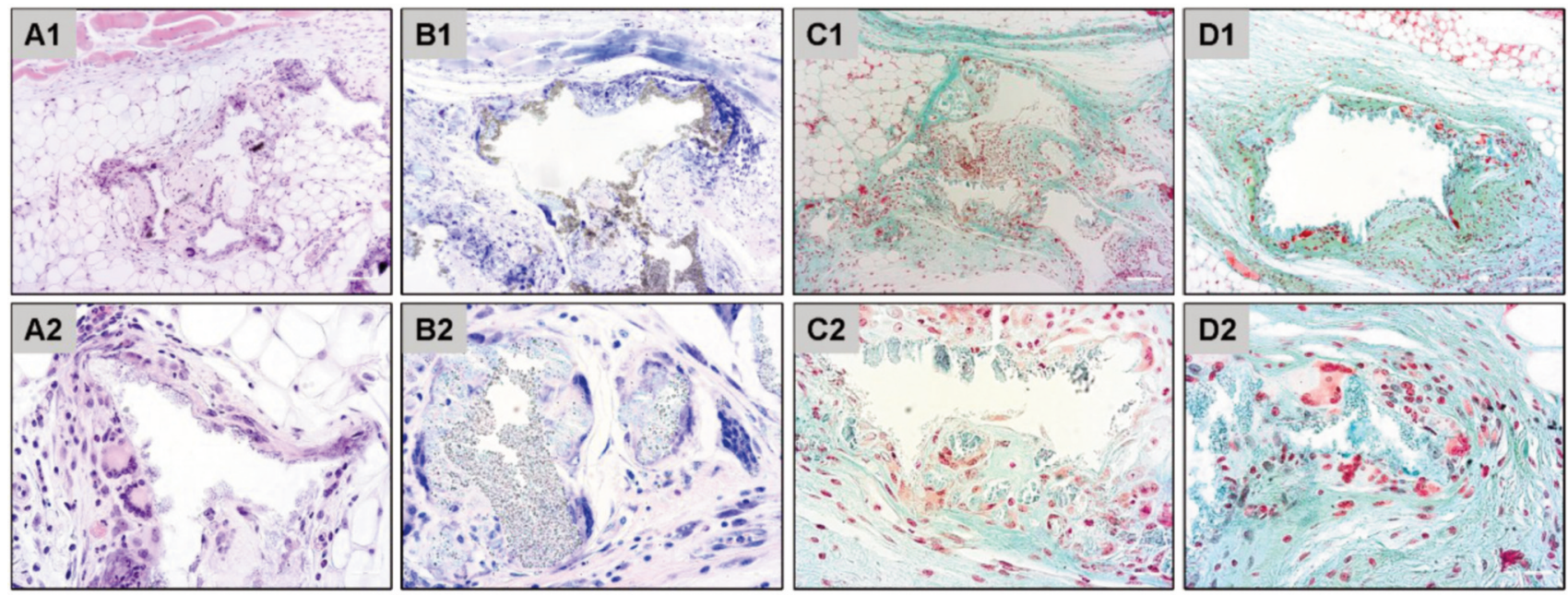

Figure 3. Exemplary histological images of subcutaneously implanted synthetic bone substitute material at day 30 post implantation stained with hematoxylin and eosin (A), Giemsa (B), Masson-Goldner (C) and Movat's pentachrome (D). Original magnification: Upper row: 10x; lower row: 40x.

x. Weigert's iron hematoxylin 10 min (note preparation!) xi. Distilled water briefly rinse xiii. Distilled water briefly rinse xiv. Sodium thiosulfate $5 \% 1 \mathrm{~min}$ xv. Distilled water briefly rinse xvi. Rinse in tap water $10 \mathrm{~min}$ xvii. Brilliant Crocein acid $10 \mathrm{~min}$ xviii. $1 \%$ Acetic acid $30 \mathrm{~s}$ xix. 5\% Phosphotungstic acid $20 \mathrm{~min}$ xx. Acetic acid $1 \% 2 \mathrm{~min}$ xxi. Ethanol 99.9\% $1 \mathrm{~min}$ xxii. Safron du Gatinais 6 min (Note preparation!) xxiii. Ethanol $99.9 \% 2 \mathrm{~min}$ xxiv. $3 \times$ Xylene 5 min each Dyeing time: approx. 3:15 h

Finally, with the Movat's pentachrome staining, all components of the connective tissue can be displayed in a single staining as detailed in Table V.

While these stains partially allow separation of different cell types, such as osteoblasts, macrophages, or granulocytes, involved in regeneration or inflammatory processes, other specialized stains, such as Giemsa, can be used for basic microscopic separation of cells (36). Moreover, some enzymatic-detection techniques, such as tartrate-resistant alkaline phosphatase (TRAP) for detection of osteoblasts, are used for the visualization of specific cell types $(37,38)$.

The processes within an implantation bed of a bone substitute can be discerned in more detail via immunohistochemistry, which allows for detection of molecules or cell (sub-)types involved in the (inflammatory) tissue reactions to a biomaterial. Many different factors have
Table V. Staining results of the Movat's pentachrome staining.

\begin{tabular}{lc}
\hline Structure & Color \\
\hline Cell nuclei & Brown-black \\
Collagen fibers & Yellow \\
Reticular fibers & Yellow \\
Mineralized bone matrix & Yellow \\
Mineralized cartilage & Blue-green \\
Osteoid & Red \\
Mucin & Blue \\
Fibrinoid substance, Fibrin & Red \\
Muscles & Red \\
Cytoplasm & Red \\
Acid glycosaminoglycans & Bright light blue \\
\hline
\end{tabular}

to be considered for successful immunohistochemical detection; these are not discussed in detail in this article. However, different guides for conducting immunohistochemistry are available from antibody manufacturers, books, and publications (39). The variables that must be considered and optimized for successful immunohistochemical detection include the respective antigens (species, expression level, sample type), epitopes, appropriate controls, sample preparation, fixation methods and fixatives, blocking steps, antigen retrieval methods, detection methods, primary and secondary antibodies, labeling methods and labels, counterstains, and mounting reagents.

For example, inflammatory processes can be detected using macrophage antibodies for differentiating between the different pro- and anti-inflammatory subtypes $(40,41)$ (Figure 4). 

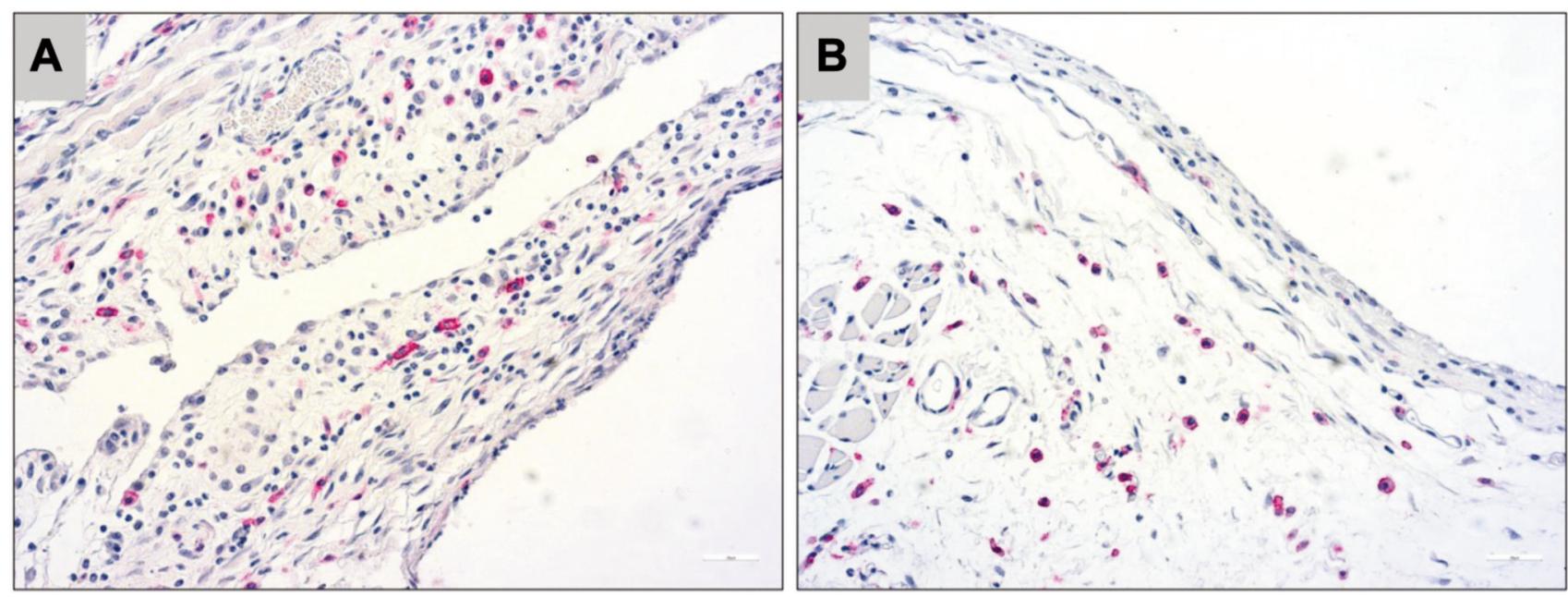

Figure 4. Exemplary histological images of immunohistochemical detection of CD163 for M2 macrophages (A) and CD11c for M1 macrophages (B) within the subcutaneous implantation bed of a resorbable magnesium membrane at day 10 post implantation. Original magnification: 20x.

\section{Analytical Methods for Preclinical Tissue Explants and Clinical Biopsies}

The first step in the analysis of biomaterial tissue reactions includes microscopic analysis of the implantation beds $(2,4$, 42-49). Different methods allow for quantitative determination of the healing processes within the implantation beds of a biomaterial. For example, a qualitative description of bony integration is particularly important, because factors such as interactions with the bone matrix, or osteoblastic growth that is reflected by osteoblastic hems, can only be described based on observations.

In general, it is useful to follow a specific protocol that defines monitoring parameters; such a procedure facilitates the comparison of different bone substitutes analyzed in the same study and allows cross-study comparisons. A scoring system for such analyses represent a semi-quantitative approach (50). Examination is generally performed by two or more experts in histology, based on an evaluation form containing different parameters (Table VI). In most cases, a score for each subject is obtained individually, and the overall healing score represents the sum of all evaluated parameters. The obtained data can be used for statistical analysis.

Finally, representative microphotographs are acquired with a light microscope combined with a digital camera; these are generally used for publication.

Histomorphometrical analyses of the different factors involved in tissue reactions to biomaterials or in (bone) tissue healing are used as a more exact method (2, 4, 42-49, $51,52)$. However, this kind of analysis requires a microscope equipped with a digital camera and a computer running an analytical software. Combined microscope systems, including motorized components such as a scanning table for digitization of histological slides, are available from different companies (Figure 5).

The costs of appropriate microscopes, digital cameras, and related computer programs vary widely. The costs of programs vary from open-source software, such as ImageJ (53), a tool suitable for different histomorphometrical analyses, to specialized software packages that can cost thousands of euros. However, costly software packages from certain manufacturers are optimally adapted for components such as a digital camera or scanning table; in contrast, such components are only occasionally compatible with opensource programs.

Histomorphometrical analysis can include a variety of biomaterial-related factors. For example, factors such as the following morphometric indices for calculation of newly formed bone in sites of regeneration (53-55):

i. Total area (TA) or total volume (TV) of a biopsy per implantation site, including both new bone, remaining bone substitute, and soft-tissue cavities (in $\mathrm{mm}^{2}$ or $\mathrm{mm}^{3}$ )

ii. Areas or volumes of newly formed bone tissue (BA or $\mathrm{BV}$ ), of remaining bone-substitute material (MA or MV), or of connective tissue (CA or $\mathrm{CV}$ ) (in $\mathrm{mm}^{2}$ or $\mathrm{mm}^{3}$ )

iii. Fractions of bone tissue (BA/TA or BV/TV), remaining bone substitute (MA/TA or MV/TV) or connective tissue (CA/MA or CV/TV), also described as the percentage or ratio (hence, no unit of measure is used)

iv. Average bone thickness (B.Th) (in mm)

v. Average bone separation, which is the thickness of softtissue cavities (B.Sp) (in $\mathrm{mm}$ )

Various other factors, such as vascularization of the implantation bed (as a percentage of the implantation area and numbers of vessels $/ \mathrm{mm}^{2}$ of the implantation bed) or numbers of different cell types, such as MNGCs, within the 
Table VI. Example of a scoring protocol for bone regeneration [score taken from (51)].

Histological score

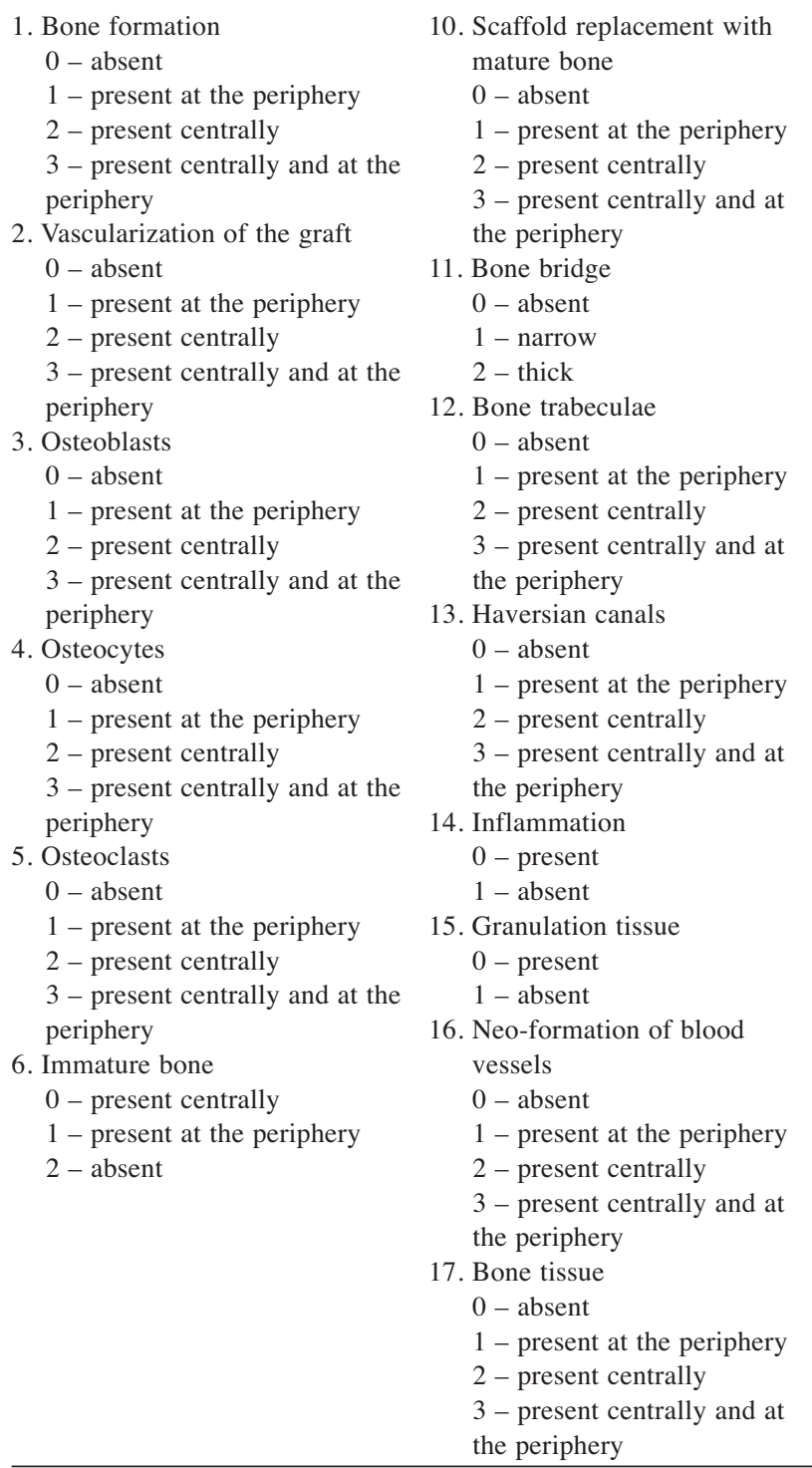

implantation bed (cells $/ \mathrm{mm}^{2}$ of the implantation bed) can be measured, counted, and related to the respective implantation area via histomorphometry (2, 4, 42-49). Altogether, histomorphometrical analyses are an appropriate method for analyzing the bone-healing process and related factors. Interestingly, the manual marking of the areas of tissue fractions is most often still necessary for measurements of these parameters (Figure 6).

Most software programs currently offer automatic or semiautomatic analyses for cell counting. However, conducting these analyses is strongly dependent on factors such as quality of the histological slides and digitization quality, which, in turn, are based on the quality of components used for digitization (e.g. resolution of the digital camera); most of all, the contrast of the respective staining is the most important factor in these assessments. Immunohistochemical stains may provide the highest contrast, while many histochemical stains do not enable sufficient separation of different tissue fractions or cell types.

In this context, we want to describe for the first time an automatic cell counting approach for detection of cell types such as pro- or anti-inflammatory macrophages within the implant beds of biomaterials using the ImageJ software package.

\section{Step-by-step Guide for Automatic Cell Counting Based on Immunohistochemically Stained Tissue Slides}

A stepwise approach using software like the freeware ImageJ that can be downloaded from https://imagej.nih.gov/ij/ can be used after adoption of the software to individual needs by the development of specific workflows or plugins. The steps are listed in Table VII.

Interestingly, for establishment of this measurement protocol the method was compared to both manual cell counting and other software-based methods that can be purchased. The results showed a continuously low tolerance for errors, which makes the present methodology most preferable as it is based on a free software package and is highly timesaving (unpublished data).

Finally, the measurements are related to the total defect or implantation area resulting in cell numbers per unit area, for example cells $/ \mathrm{mm}^{2}$ ). This calculated cell numbers allows then to compare the tissue reactions to two or more biomaterials analyzed in one study as previously shown (4, 5, 27, 42, 47, 56, 57). Furthermore, the results enable comparison of new study results with those from former studies using the same study conditions, i.e. the same implantation model, the same histological preparation and immunostainings as well as the same microscope setting.

\section{Representative Results}

In this context, every biomaterial, such as bone substitutes, induces an inflammatory response and inflammatory tissue response cascade, the so-called foreign body reaction to biomaterials (7-10). In this inflammatory cascade, macrophages are key cellular components because they regulate different processes in the implantation bed (7-10). Interestingly, MNGCs in the implant beds of both natural-based bone-substitute materials and synthetic materials appear to possess the phenotype of foreign body giant cells (9). It has been long- 

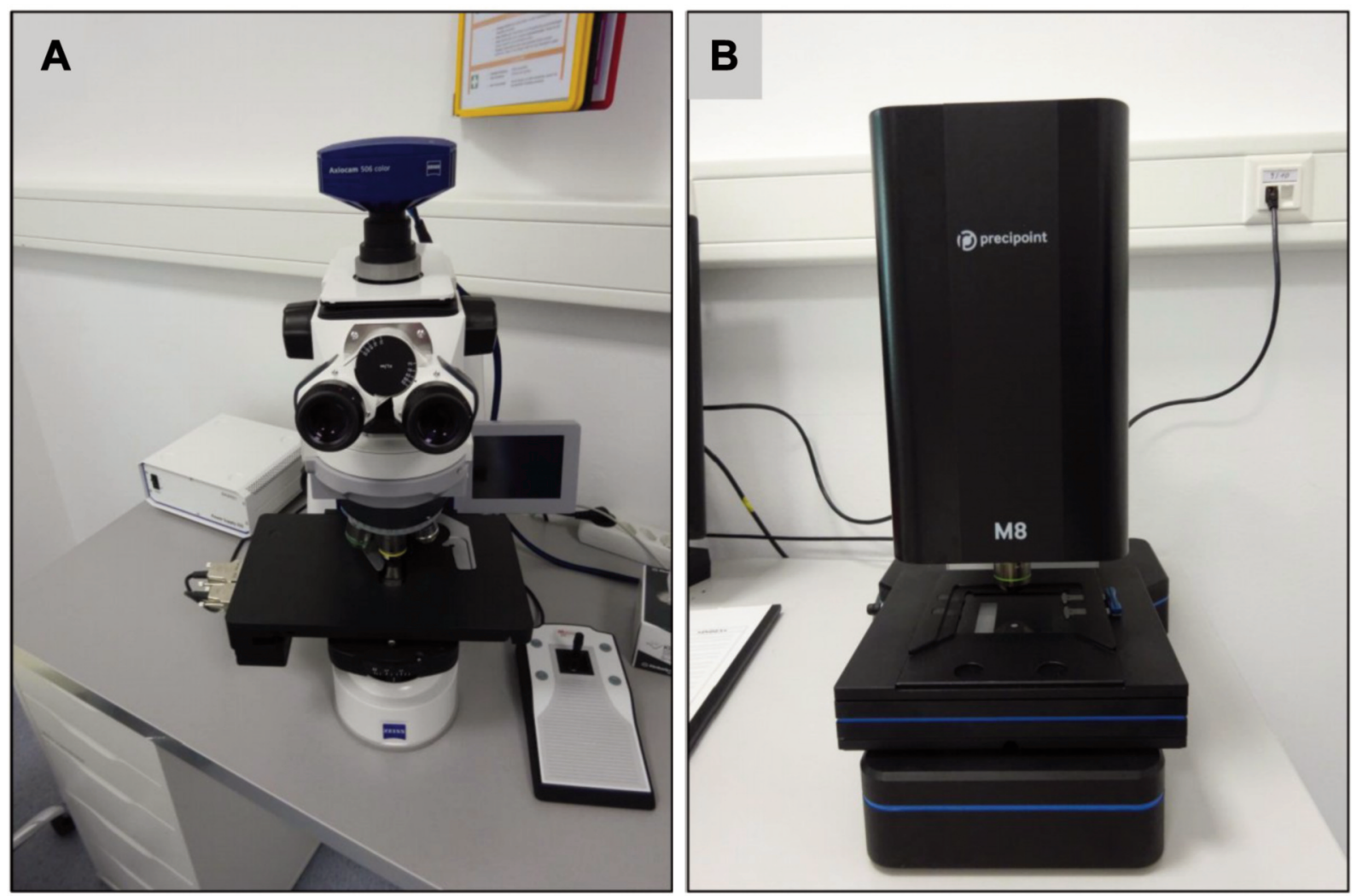

Figure 5. A: A conventional light microscope (Axioscope 5; Zeiss, Oberkochen, Germany) equipped with a scanning table. B: Newly developed digital microscope that allows for microscopy only on a digital basis (Precipoint M8; Precipoint GmbH, Freising, Germany).

supposed that MNGCs found in the implant beds of bone substitutes based on calcium phosphates, such as calcified bone matrix, are osteoclasts, i.e. physiologically derived cells involved in bone metabolism. However, more recent studies have shown that this cell type is of inflammatory origin (9). Both macrophages and MNGCs express pro- and antiinflammatory molecules, such as the vascular endothelial growth factor and heme oxygenase, which have major influence on vascularization of the implant bed of bone substitutes $(9,11)$. Vascularization is a key factor for bonetissue regeneration and process of osteoconduction (Figure 3); thus, the inflammatory response to a material is associated with the bone healing process and other various pathways $(8,9)$.

Both preclinical and clinical studies and the related biopsies are used to determine not only the regenerative effects of biomaterials, but also the material-related inflammatory responses and associated processes such as biodegradation.

In the past decades, the described methods have been used to compare tissue reactions to many different bone substitutes. In this context, their application can substantiate the long-term stability of xenogeneic biomaterials based on bovine bone that may be related to reduced induction of MNGCs $(2,58)$. Moreover, it was shown that differences in granule size, shape and porosity of five different $\beta$-tricalcium phosphate $(\beta$-TCP)based bone substitute materials influenced their integration within the implantation bed and the formation of tartrateresistant acid phosphatase (TRAP)-positive and TRAP-negative MNGCs, as well as the rate of vascularization (56). It was concluded that variations in the physical properties of a bone substitute material clearly influence the extent of the inflammatory reaction. In another study, it was revealed that different chemical compositions of three bone substitute materials, namely hydroxyapatite (HA), $\beta$-TCP and a mixture of both with a HA/TCP ratio of $60 / 40 \mathrm{wt} \%$, significantly influenced the material-related tissue responses (5). TCP induced significantly higher numbers of MNGCs compared to HA. Furthermore, the vascularization of the implantation bed of TCP was significantly higher than that of HA implantation beds. The mixture of bone substitutes combined the properties of both. These study results lead to the conclusion that the combination of both compounds is useful for generating a scaffold for rapid vascularization and integration during the early time points after implantation and for setting up relatively slow degradation.

Finally, the methods described above were used to analyze the tissue reactions to different injectable bone substitute 


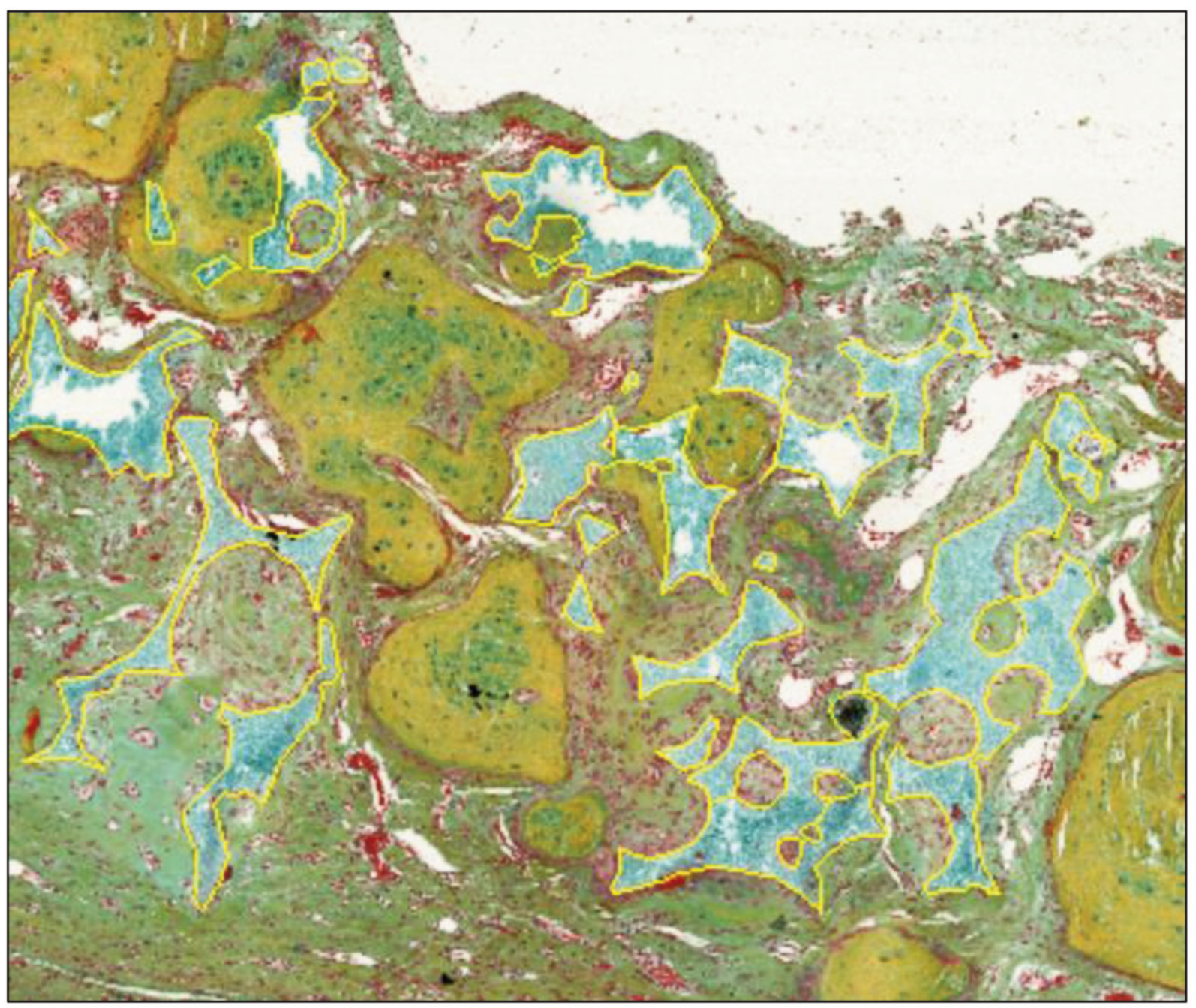

Figure 6. Manual marking (yellow line) of the remaining bone substitute granules for evaluation of the regenerative capacities of a synthetic bone substitute material using ImageJ software.

materials, leading to the elucidation of their integration behavior $(44,59,60)$.

Altogether, these methods allow for the comparison of the tissue reactions to a variety of biomaterials and help in analyzing their biocompatibility.

\section{Discussion}

Although the histological preparation of tissue samples or biopsies is relatively stable and applicable, every step includes sources of error that might be of vital importance for the subsequent steps and can also significantly influence the overall success of tissue sample processing.

Initially, the fixation process is a critical step as failure can have major influence mainly onto the following (immuno-) histochemical staining. Thus, it is of great importance to choose the correct fixation medium for the detection methods which are to be used later. Furthermore, insufficient fixation can cause embedding and cutting failures.

Subsequently, the embedding process is also of crucial importance as it can significantly affect processes such as cutting and staining. While paraffin embedding is a relatively widely applicable method, plastic embedding is particularly more challenging. This can be due to the infiltration process as a biopsy must be infiltrated for a long time span for complete penetration to be achieved. Thus, most problems arise from too short and therefore insufficient plastic infiltration. This problem can be solved by infiltration of tissue samples under vacuum. Furthermore, the embedding process can be impaired by embedding media or impurities within the embedding medium. 
Table VII. Exemplary stepwise approach of a measurement process for bone regeneration based on ImageJ.

(a) Re-calibration of a total scan

- Zoom into the total scan on the scalebar

- Measure the scalebar from start to finish with the "straight" tool

- After measurement $\rightarrow$ Set calibration

- In the header of ImageJ

$>$ Analyze

$>$ Set Scale

- Settings window opens

$>$ Specify "Known distance", e.g. 5000 for $5 \mathrm{~mm}$ measuring bar length

$>$ Specify "Unit of length" (e.g. $\mu \mathrm{m})$

Result: Values are later specified in the window "Results" in $\mu \mathrm{m}$ instead of in pixels

(b) Duplication of the image

- After calibration, the calibrated original image should be duplicated

$>$ Right mouse click

> Choose "Duplicate"

$>$ Confirm with "OK"

(c) Mark of the "Regions Of Interest" (ROIs)

- Use the tool "Polygon selection"

- Start to set the border

- Note: To move within the image without interrupting the mark process

it is necessary to press the spacebar and to move the image with the mouse

- Close the border with a right mouse click

- Press "T"

$>$ ROI-manager window opens

$>$ First ROI is displayed in window

- The mark process can be repeated any number of times

- To display all marked ROIs within an image, check the respective labels in the ROI manager

$\checkmark$ Show all

$\checkmark$ Labels

Linkage of individual ROIs (if necessary)

- Hold down the Ctrl key

> Mark all ROIs that should be combined in the ROI-manager

- After the mark process

$>$ Click on "More" in the sidebar of the ROI-manager

$>$ Choose "XOR"

$>$ Press "T"

- A new ROI-file is displayed in the ROI-manager and the new combined ROI is now shown in the image.

Save the (linked) ROI(s)

- Mark the ROI in the ROI-manager

$>$ Right click

$>$ "Save"

$>$ Name the ROI(s)

$>$ "Save"

Measurement of the ROI area

- Mark the ROI to be measured in the ROI-manager

$>$ Press "Strg"+"M" or press the button Analyze $\rightarrow$ Measure

• "Results" window opens
Definition of the color values

- In the ROI Manager the linked ROI file is marked

1. Select in the header of Image-J:

$>$ Edit

$>$ Clear Outside

$>$ Note: "Clear Outside" must be applied so that

- Cell nuclei that are not co-stained by the color threshold outside the ROI label

$>$ macrophages outside the ROI mark are not counted

2. Select in the header of Image-J:

$>$ Image

$>$ Adjust

$>$ Color Threshold

- Hint: If the specified threshold values are insufficient for the evaluation, only the saturation value should be adjusted.

$>$ All other settings remain constant!

- Minimize the threshold window, because otherwise settings will be transferred to the duplicate and thus may falsify the complete evaluation.

- New settings window opens

- Color-Threshold Settings

$>$ Hue: 191-255

$>$ Saturation: 50-255

$>$ Brightness: 0-255

> Thresholding method: Default

$>$ Thresholding color: Red

$>$ Color space: HSB

$>$ Check mark at

$\checkmark$ Dark background

- Threshold window must be minimized

Create mask according to Color-Threshold setting

- Mark the ROI

- Select in the header of Image-J:

$>$ Analyze

$>$ Analyze particles

- New settings window opens, select the following settings:

- Size: 1-Infinity

$>$ Show: Masks

$>$ Check marks only at

$\checkmark$ Display results

$\checkmark$ Clear results

$>$ After entering the settings, press "ok"

- New window opens with the label "Mask of picture name" \& the defined particles in black and white will be opened

Define the cell nuclei

- Use the duplicate

- Split the colors of the duplicate $\rightarrow$ select in the header of Image-J:

$>$ Image

$>$ Color

$>$ Split Channels

- Three black and white pictures open with the captions:

$>$ "picture name (red)"

$>$ "picture name (green)"

$>$ "picture name (blue)"

- Use the image with the caption "picture name (red)", the others can be closed

- Insert the ROI into the red duplicate image 
- Select in the header of Image-J:

$>$ Process

$>$ Find Maxima settings:

$>$ Prominence $>20$

$>$ Check mark at:

$\checkmark$ Light background

$>$ Output type: Maxima within Tolerance

- New window with Maxima opens

$>$ White background with black dots

- Hint: If the Maxima image has a black background with white dots,

follow these steps:

$>$ Process $\rightarrow$ Binary $\rightarrow$ Options

$>$ Window opens

$>$ Remove check mark at: $\square$ black background

Combined evaluation of Mask \& Maxima image

- Select in the header of Image-J:

$>$ Process

$>$ Image calculator

- New settings window opens, select the following settings:

> Image 1: "Mask of picture name"

$>$ Operation: AND

$>$ Image 2: "picture name (red) Maxima"

$>$ Check mark at

$\checkmark$ Create new window

- New window with the overlay opens
Counting of positive cells/macrophages

- Use last newly opened overlay window

- Select in the header of Image-J:

$>$ Edit

$>$ Selection

$\checkmark$ Create Selection

- Yellow connecting lines appear in the window

- Select in the header of Image-J:

$>$ Analyze

$>$ Analyze Particles

$>$ New settings window opens, select the following settings:

> Size: 2-Infinity

$>$ Show: Masks

$>$ Check marks only at:

$\checkmark$ Display results

$\checkmark$ Clear results

$>$ After entering the settings, press "ok"

- Query "Save results?" opens

$>$ Select "No"

- In the "Results" window you can see the number of macrophages, the last number at the bottom left (first column last line) of the Results window corresponds to macrophage number
In general, one of the major problems is incorrect placement of the biopsy within the embedding medium, which causes subsequent inaccurate sectioning of the biopsy. This problem can easily be solved in the case of paraffin-embedded biopsies as they can be melted and rapidly re-embedded. In contrast, the re-embedding of plastic-embedded samples is much more challenging if not impossible. In the case of such problems, most often only complete re-cutting of the blocks is helpful.

Further issues may occur during the processing of histochemical staining most often caused by inadequate dewaxing or de-plastination. These issues produce problems with adherence of the dyes and thus lead to incorrect staining results. Additionally, problems can be caused by incorrect dyeing times, incorrect mixing of staining solution, or prolonged time intervals between the staining procedure and the placement of coverslips.

The complete process of immunohistochemical staining includes many different error sources. This includes antibody concentration, antibody exposure time, incorrect pretreatment of the tissue, inappropriate choice of detection kit or the disregarding chromogen solubility, and the omission of a required (protein) blocking solution such as that against endogenous peroxidase or alkaline phosphatase.

Moreover, a variety of issues may occur during histopathological analysis, including the choice of the correct staining for the identification of different cell types involved in the tissue reactions to a biomaterial or the lack of identification of (remnants of) a biomaterial. Problems also arise in histomorphometrical analysis of tissue samples. For example, this includes the digitization process and related incorrect illumination of a microscope slide. Not least, the (semi-)quantitative analysis of tissue samples causes many issues in determination of the implantation area and the correct distinction of individual cells.

Altogether, the present techniques are adequate for tissue reactions to a variety of biomaterials to be analyzed systematically. Although a variety of problems can occur during the different preparation and analytical steps, the methods can be performed in a satisfactory manner and can be improved over time and with gain of experience.

\section{Conflicts of Interest}

The Authors have nothing to disclose.

\section{Authors' Contributions}

The work presented here was carried out in collaboration between all Authors. Mik. B and OJ designed the study. CL, AP, MA, TL and Mil. B collected the data. CL, AP, MA, TL, Mil. B and Mik. B wrote the first draft of the article. OJ and Mik. B drafted the article. OJ and Mik. B revised the article. The research consortium completed the final manuscript. All Authors read and approved the final article. 


\section{Acknowledgements}

This work was solely funded by the research funds of the Authors.

\section{References}

1 Kapogianni E, Barbeck M, Jung O, Arslan A, Kuhnel L, Xiong X, Krastev R, Friedrich RE, Schnettler R, Fienitz $T$ and Rothamel D: Comparison of material-mediated bone regeneration capacities of sintered and non-sintered xenogeneic bone substitutes via $2 \mathrm{~d}$ and $3 \mathrm{~d}$ data. In Vivo 33(6): 2169-2179, 2019. PMID: 31662553. DOI: 10.21873 /invivo.11719

2 Barbeck M, Udeabor S, Lorenz J, Schlee M, Holthaus MG, Raetscho N, Choukroun J, Sader R, Kirkpatrick CJ and Ghanaati S: High-temperature sintering of xenogeneic bone substitutes leads to increased multinucleated giant cell formation: In vivo and preliminary clinical results. J Oral Implantol 41(5): e212-222, 2015. PMID: 25105868. DOI: 10.1563/aaid-joi-D-14-00168

3 Barbeck M, Dard M, Kokkinopoulou M, Markl J, Booms P, Sader RA, Kirkpatrick CJ and Ghanaati S: Small-sized granules of biphasic bone substitutes support fast implant bed vascularization. Biomatter 5: e1056943, 2015. PMID: 26083163. DOI: $10.1080 / 21592535.2015 .1056943$

4 Barbeck M, Serra T, Booms P, Stojanovic S, Najman S, Engel E, Sader R, Kirkpatrick CJ, Navarro M and Ghanaati S: Analysis of the in vitro degradation and the in vivo tissue response to bi-layered 3D-printed scaffolds combining PLA and biphasic PLA/bioglass components - guidance of the inflammatory response as basis for osteochondral regeneration. Bioact Mater 2(4): 208-223, 2017. PMID: 29744431. DOI: 10.1016/j.bioactmat.2017.06.001

5 Ghanaati S, Barbeck M, Detsch R, Deisinger U, Hilbig U, Rausch V, Sader R, Unger RE, Ziegler G and Kirkpatrick CJ: The chemical composition of synthetic bone substitutes influences tissue reactions in vivo: Histological and histomorphometrical analysis of the cellular inflammatory response to hydroxyapatite, beta-tricalcium phosphate and biphasic calcium phosphate ceramics. Biomed Mater 7(1): 015005, 2012. PMID: 22287541. DOI: $10.1088 / 1748-6041 / 7 / 1 / 015005$

6 Peric Kacarevic Z, Kavehei F, Houshmand A, Franke J, Smeets R, Rimashevskiy D, Wenisch S, Schnettler R, Jung O and Barbeck M: Purification processes of xenogeneic bone substitutes and their impact on tissue reactions and regeneration. Int J Artif Organs 41(11): 789-800, 2018. PMID: 29707988. DOI: $10.1177 / 0391398818771530$

7 Anderson JM, Rodriguez A and Chang DT: Foreign body reaction to biomaterials. Semin Immunol 20(2): 86-100, 2008. PMID: 18162407. DOI: 10.1016/j.smim.2007.11.004

8 Barbeck M, Motta A, Migliaresi C, Sader R, Kirkpatrick CJ and Ghanaati S: Heterogeneity of biomaterial-induced multinucleated giant cells: Possible importance for the regeneration process? J Biomed Mater Res A 104(2): 413-418, 2016. PMID: 26422451. DOI: $10.1002 / \mathrm{jbm} . \mathrm{a} .35579$

9 Barbeck M, Booms P, Unger R, Hoffmann V, Sader R, Kirkpatrick CJ and Ghanaati S: Multinucleated giant cells in the implant bed of bone substitutes are foreign body giant cells-new insights into the material-mediated healing process. J Biomed Mater Res A 105(4): 1105-1111, 2017. PMID: 28093892. DOI: 10.1002/jbm.a.36006
$10 \mathrm{Hu}$ WJ, Eaton JW, Ugarova TP and Tang L: Molecular basis of biomaterial-mediated foreign body reactions. Blood 98(4): 12311238, 2001. PMID: 11493475. DOI: 10.1182/blood.v98.4.1231

11 Anderson JM and Jones JA: Phenotypic dichotomies in the foreign body reaction. Biomaterials 28(34): 5114-5120, 2007. PMID: 17706278. DOI: 10.1016/j.biomaterials.2007.07.010

12 Hopwood D: Fixatives and fixation: A review. Histochem J 1(4): 323-360, 1969. PMID: 4113286. DOI: 10.1007/BF01003278

13 Buesa RJ: Histology without formalin? Ann Diagn Pathol 12(6): 387-396, 2008. PMID: 18995201. DOI: 10.1016/j.anndiagpath. 2008.07.004

14 Iwaniec UT, Wronski TJ and Turner RT: Histological analysis of bone. Methods Mol Biol 447: 325-341, 2008. PMID: 18369927. DOI: 10.1007/978-1-59745-242-7_21

15 Olert J, Wiedorn KH, Goldmann T, Kühl H, Mehraein Y, Scherthan H, Niketeghad F, Vollmer E, Müller AM and MüllerNavia J: Hope fixation: A novel fixing method and paraffinembedding technique for human soft tissues. Pathol Res Pract 197(12): 823-826, 2001. DOI: 10.1078/0344-0338-00166

16 Werner M, Chott A, Fabiano A and Battifora H: Effect of formalin tissue fixation and processing on immunohistochemistry. Am J Surg Pathol 24(7): 1016-1019, 2000. PMID: 10895825. DOI: 10.1097/00000478-200007000-00014

17 Hutmacher DW, Schantz JT, Lam CX, Tan KC and Lim TC: State of the art and future directions of scaffold-based bone engineering from a biomaterials perspective. J Tissue Eng Regen Med 1(4): 245260, 2007. PMID: 18038415. DOI: 10.1002/term.24

18 Bendayan M, Nanci A and Kan FW: Effect of tissue processing on colloidal gold cytochemistry. J Histochem Cytochem 35(9): 983-996, 1987. PMID: 3302022. DOI: 10.1177/35.9.3302022

19 Hornbeck C, Emmanual J and Bloebaum RD: A comparative study of three paraffin media for preparing large decalcified bone sections. J Histotechnol 9(4): 227-229, 1986.

20 Skinner RA: Decalcification of bone tissue. In: Handbook of Histology Methods for Bone and Cartilage. An YH (ed.). Humana Press, pp. 167-184, 2010.

21 Erben RG: Embedding of bone samples in methylmethacrylate: An improved method suitable for bone histomorphometry, histochemistry, and immunohistochemistry. J Histochem Cytochem 45(2): 307-13, 1997. PMID: 9016319. DOI: $10.1177 / 002215549704500215$

22 Baskin TI, Busby CH, Fowke LC, Sammut M and Gubler F: Improvements in immunostaining samples embedded in methacrylate: Localization of microtubules and other antigens throughout developing organs in plants of diverse taxa. Planta 187(3): 405-413, 1992. DOI: 10.1007/BF00195665

23 Newman GR and Hobot JA: Modern acrylics for postembedding immunostaining techniques. J Histochem Cytochem 35(9): 971-981, 1987. PMID: 3302021. DOI: 10.1177/35. 9.3302021

24 Ghanaati S, Barbeck M, Booms P, Lorenz J, Kirkpatrick CJ and Sader RA: Potential lack of "standardized" processing techniques for production of allogeneic and xenogeneic bone blocks for application in humans. Acta Biomater 10(8): 3557-3562, 2014. PMID: 24769111. DOI: 10.1016/j.actbio.2014.04.017

25 Giesenhagen B, Martin N, Donkiewicz P, Peric Kacarevic Z, Smeets R, Jung O, Schnettler R and Barbeck M: Vertical bone augmentation in a single-tooth gap with an allogenic bone ring: Clinical considerations. J Esthet Restor Dent 30(6): 480-483, 2018. PMID: 30070751. DOI: 10.1111/jerd.12392 
26 Korzinskas T, Jung O, Smeets R, Stojanovic S, Najman S, Glenske K, Hahn M, Wenisch S, Schnettler R and Barbeck M: In vivo analysis of the biocompatibility and macrophage response of a non-resorbable ptfe membrane for guided bone regeneration. Int J Mol Sci 19(10): 2952, 2018. PMID: 30262765. DOI: 10.3390/ijms19102952

27 Sieger D, Korzinskas T, Jung O, Stojanovic S, Wenisch S, Smeets R, Gosau M, Schnettler R, Najman S and Barbeck M: The addition of high doses of hyaluronic acid to a biphasic bone substitute decreases the proinflammatory tissue response. Int J Mol Sci 20(8): 1969, 2019. PMID: 31013636. DOI: $10.3390 / \mathrm{ijms} 20081969$

28 Plattner H and Bachmann L: Cryofixation: A tool in biological ultrastructural research. In: International review of cytology. Bourne GH, Danielli JF and Jeon KW (eds.). Academic Press: New York, pp. 237-304, 1982.

29 Meng H, Janssen PM, Grange RW, Yang L, Beggs AH, Swanson LC, Cossette SA, Frase A, Childers MK, Granzier H, Gussoni E and Lawlor MW: Tissue triage and freezing for models of skeletal muscle disease. J Visualized Exp 89: 51586, 2014. PMID: 25078247. DOI: $10.3791 / 51586$

30 Santos RR, Tharasanit T, Figueiredo JR, van Haeften T and van den Hurk R: Preservation of caprine preantral follicle viability after cryopreservation in sucrose and ethylene glycol. Cell Tissue Res 325(3): 523-531, 2006. PMID: 16645860. DOI: 10.1007/s00441-006-0193-5

31 Hewitson TD, Wigg B and Becker GJ: Tissue preparation for histochemistry: Fixation, embedding, and antigen retrieval for light microscopy. Meth Mol Biol 611: 3-18, 2010. PMID: 19960318. DOI: 10.1007/978-1-60327-345-9_1

32 Fischer AH, Jacobson KA, Rose J and Zeller R: Hematoxylin and eosin staining of tissue and cell sections. CSH Protocols 2008: pdb.prot4986, 2008. PMID: 21356829. DOI: 10.1101/pdb. prot4986

33 Wittekind D: Traditional staining for routine diagnostic pathology including the role of tannic acid. 1. Value and limitations of the hematoxylin-eosin stain. Biotech Histochem 78(5): 261-270, 2003. PMID: 14989644. DOI: 10.1080/ 10520290310001633725 .

34 Gruber HE and Imgram JA: Basic staining and histochemical techniques and immunohistochemical localizations using bone sections. In: Handbook of Histology Methods for Bone and Cartilage. An YH (ed.). Humana Press: Totowa, pp. 281-286, 2010.

35 Rentsch C, Schneiders W, Manthey S, Rentsch B and Rammelt S: Comprehensive histological evaluation of bone implants. Biomatter 4: e27993, 2014. PMID: 24504113. DOI: 10.4161/ biom. 27993

36 van der Loos CM: Multiple immunoenzyme staining: Methods and visualizations for the observation with spectral imaging. J Histochem Cytochem 56(4): 313-328, 2008. PMID: 18158282. DOI: $10.1369 /$ jhc. 2007.950170

37 Gomori G: The study of enzymes in tissue sections. American J Clin Pathol 16(6): 347-352, 1946. PMID: 18158282. DOI: 10.1093/ajcp/16.6.347

38 Nilsen R and Magnusson BC: Enzyme histochemistry of induced heterotropic bone formation in guinea-pigs. Arch Oral Biol 24(10-11): 833-841, 1979. PMID: 44466. DOI: 10.1016/00039969(79)90047-5

39 Kabiraj A, Gupta J, Khaitan T and Bhattacharya PT: Principle and techniques of immunohistochemistry - a review. Int J Biol
Med Res 6(3): 5204-5210, 2015.

40 Brown BN, Valentin JE, Stewart-Akers AM, McCabe GP and Badylak SF: Macrophage phenotype and remodeling outcomes in response to biologic scaffolds with and without a cellular component. Biomaterials 30(8): 1482-1491, 2009. PMID: 19121538. DOI: 10.1016/j.biomaterials.2008.11.040

41 Badylak SF, Valentin JE, Ravindra AK, McCabe GP and Stewart-Akers AM: Macrophage phenotype as a determinant of biologic scaffold remodeling. Tissue Eng Part A 14(11): 18351842, 2008. PMID: 18950271. DOI: 10.1089/ten.tea.2007.0264

42 Barbeck M, Najman S, Stojanovic S, Mitic Z, Zivkovic JM, Choukroun J, Kovacevic P, Sader R, Kirkpatrick CJ and Ghanaati $\mathrm{S}$ : Addition of blood to a phycogenic bone substitute leads to increased in vivo vascularization. Biomed Mater 10(5): 055007, 2015. PMID: 26359820. DOI: 10.1088/1748-6041/10/5/055007

43 Fuchs S, Ghanaati S, Orth C, Barbeck M, Kolbe M, Hofmann A, Eblenkamp M, Gomes M, Reis RL and Kirkpatrick CJ: Contribution of outgrowth endothelial cells from human peripheral blood on in vivo vascularization of bone tissue engineered constructs based on starch polycaprolactone scaffolds. Biomaterials 30(4): 526-534, 2009. PMID: 18977026. DOI: $10.1016 /$ j.biomaterials.2008.09.058

44 Ghanaati S, Barbeck M, Hilbig U, Hoffmann C, Unger RE, Sader RA, Peters F and Kirkpatrick CJ: An injectable bone substitute composed of beta-tricalcium phosphate granules, methylcellulose and hyaluronic acid inhibits connective tissue influx into its implantation bed in vivo. Acta Biomater 7(11): 4018-4028, 2011. PMID: 21784183. DOI: 10.1016/j.actbio. 2011.07.003

45 Ghanaati S, Fuchs S, Webber MJ, Orth C, Barbeck M, Gomes ME, Reis RL and Kirkpatrick CJ: Rapid vascularization of starch-poly(caprolactone) in vivo by outgrowth endothelial cells in co-culture with primary osteoblasts. J Tissue Eng Regen Med 5(6): e136-143, 2011. PMID: 21604380. DOI: 10.1002/term.373

46 Ghanaati S, Udeabor SE, Barbeck M, Willershausen I, Kuenzel O, Sader RA and Kirkpatrick CJ: Implantation of silicon dioxide-based nanocrystalline hydroxyapatite and pure phase beta-tricalciumphosphate bone substitute granules in caprine muscle tissue does not induce new bone formation. Head Face Med 9: 1, 2013. PMID: 23286366. DOI: $10.1186 / 1746-160 x-9-1$

47 Barbeck M, Unger RE, Booms P, Dohle E, Sader RA, Kirkpatrick CJ and Ghanaati S: Monocyte preseeding leads to an increased implant bed vascularization of biphasic calcium phosphate bone substitutes via vessel maturation. J Biomed Mater Res A 104(12): 2928-2935, 2016. PMID: 27419378. DOI: 10.1002/jbm.a.35834

48 Unger RE, Ghanaati S, Orth C, Sartoris A, Barbeck M, Halstenberg S, Motta A, Migliaresi C and Kirkpatrick CJ: The rapid anastomosis between prevascularized networks on silk fibroin scaffolds generated in vitro with cocultures of human microvascular endothelial and osteoblast cells and the host vasculature. Biomaterials 31(27): 6959-6967, 2010. PMID: 20619788. DOI: $10.1016 /$ j.biomaterials.2010.05.057

49 Blume O, Hoffmann L, Donkiewicz P, Wenisch S, Back M, Franke J, Schnettler R and Barbeck M: Treatment of severely resorbed maxilla due to peri-implantitis by guided bone regeneration using a customized allogenic bone block: A case report. Materials 10(10) 1213, 2017. PMID: 29065477. DOI: $10.3390 / \mathrm{ma10101213}$ 
50 Solchaga LA, Yoo JU, Lundberg M, Dennis JE, Huibregtse BA, Goldberg VM and Caplan AI: Hyaluronan-based polymers in the treatment of osteochondral defects. J Orthopaed Res 18(5): 773780, 2000. PMID: 11117300. DOI: 10.1002/jor.1100180515

51 Parfitt AM, Drezner MK, Glorieux FH, Kanis JA, Malluche H, Meunier PJ, Ott SM and Recker RR: Bone histomorphometry: Standardization of nomenclature, symbols, and units. Report of the asbmr histomorphometry nomenclature committee. J Bone Mineral Res 2(6): 595-610, 1987. PMID: 3455637. DOI: 10.1002/jbmr.5650020617

52 Eriksen EF, Axelrod DW and Melsen F: Bone Histomorphometry. Raven Press: New York, 1994.

53 Doube M, Kłosowski MM, Arganda-Carreras I, Cordelières FP, Dougherty RP, Jackson JS, Schmid B, Hutchinson JR and Shefelbine SJ: Bonej: Free and extensible bone image analysis in ImageJ. Bone 47(6): 1076-1079, 2010. PMID: 20817052. DOI: $10.1016 /$ j.bone. 2010.08 .023

54 Malluche HH, Sherman D, Meyer W and Massry SG: A new semiautomatic method for quantitative static and dynamic bone histology. Calcified Tissue Int 34(5): 439-448, 1982. PMID: 6817891. DOI: $10.1007 / \mathrm{BF} 02411282$

55 Anderson C: Histomorphometry of bone. JClin Pathol 36(12): 713, 1983. PMID: 16811151. DOI: 10.1136/jcp.36.12.1323

56 Ghanaati S, Barbeck M, Orth C, Willershausen I, Thimm BW, Hoffmann C, Rasic A, Sader RA, Unger RE, Peters F and Kirkpatrick CJ: Influence of beta-tricalcium phosphate granule size and morphology on tissue reaction in vivo. Acta Biomater 6(12): 4476-4487, 2010. PMID: 22287541. DOI: 10.1016/ j.actbio. 2010.07 .006
57 Ghanaati S, Barbeck M, Lorenz J, Stuebinger S, Seitz O, Landes C, Kovacs AF, Kirkpatrick CJ and Sader RA: Synthetic bone substitute material comparable with xenogeneic material for bone tissue regeneration in oral cancer patients: First and preliminary histological, histomorphometrical and clinical results. Ann Maxillofac Surg 3(2): 126-138, 2013. PMID: 24205471. DOI: $10.4103 / 2231-0746.119221$

58 Barbeck M, Udeabor SE, Lorenz J, Kubesch A, Choukroun J, Sader RA, Kirkpatrick CJ and Ghanaati S: Induction of multinucleated giant cells in response to small sized bovine bone substitute (bio-oss) results in an enhanced early implantation bed vascularization. Ann Maxillofac Surg 4(2): 150-157, 2014. PMID: 25593863. DOI: 10.4103/2231-0746.147106

59 Barbeck M, Hoffmann C, Sader R, Peters F, Hubner WD, Kirkpatrick CJ and Ghanaati S: Injectable bone substitute based on beta-tcp combined with a hyaluronan-containing hydrogel contributes to regeneration of a critical bone size defect towards restitutio ad integrum. J Oral Implantol 42(2): 127-137, 2016. PMID: 26301338. DOI: 10.1563/aaid-joi-D-14-00203

60 Barbeck M, Jung O, Smeets R, Gosau M, Schnettler R, Rider P, Houshmand A and Korzinskas T: Implantation of an injectable bone substitute material enables integration following the principles of guided bone regeneration. In Vivo 34(2): 557-568, 2020. PMID: 32111754. DOI: 10.21873/invivo.11808

Received August 1, 2020

Revised August 27, 2020

Accepted September 2, 2020 